\title{
A Dynamic Clustering Mechanism Considering Energy Efficiency in the Wireless Sensor Network
}

\author{
Hwan $\mathrm{Kim}^{+} \cdot$ Sanghyun Ahn ${ }^{++}$
}

\begin{abstract}
In the cluster mechanism of the wireless sensor network, the network lifetime is affected by how cluster heads are selected. One of the representative clustering mechanisms, the low-energy adaptive clustering hierarchy (LEACH), selects cluster heads periodically, resulting in high energy consumption in cluster reconstruction. On the other hand, the adaptive clustering algorithm via waiting timer (ACAWT) proposes a non-periodic re-clustering mechanism that reconstructs clusters if the remaining energy level of a cluster head reaches a given threshold. In this paper, we propose a re-clustering mechanism that uses multiple remaining node energy levels and does re-clustering when the remaining energy level of a cluster head reaches one level lower. Also, in determining cluster heads, both of the number of neighbor nodes and the remaining energy level are considered so that cluster heads can be more evenly placed. From the simulations based on the Qualnet simulator, we validate that our proposed mechanism outperforms ACAWT in terms of the network lifetime.
\end{abstract}

Keywords : Wireless Sensor Network, Clustering, Cluster Head, Energy Efficiency

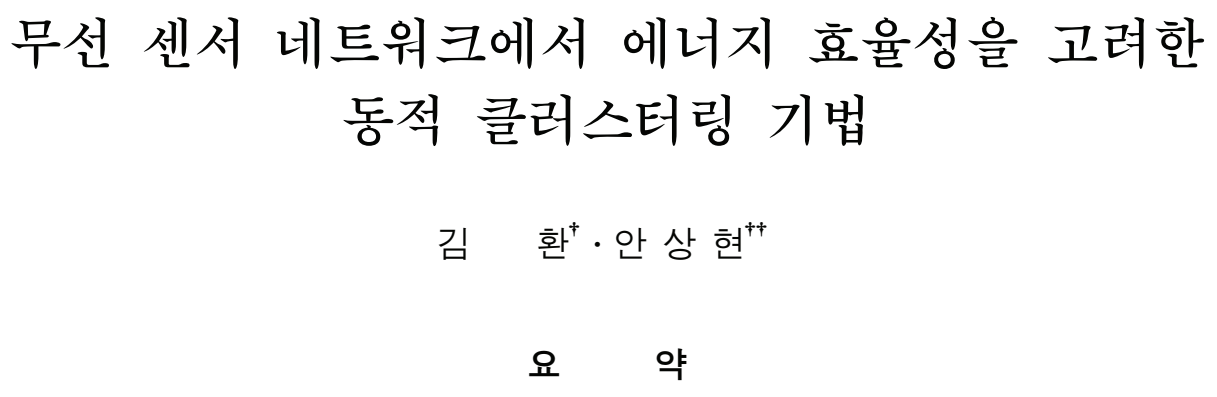

무선 센서 네트워크에서 클러스터링 방식의 네트워크 수명은 클러스터 헤드 결정 방법에 의해서 영향을 받는다. 대표적인 클러스터링 방식 인 LEACH(Low-Energy Adaptive Clustering Hierarchy)의 경우 주기적으로 클러스터 헤드를 선택함으로써 클러스터 재구축으로 인한 에너지 소모가 큰 단점이 있다. 한편 ACAWT(Adaptive Clustering Algorithm via Waiting Timer)는 클러스터 헤드의 잔여 에너지 수준이 하나의 특 정 임계치에 도달하면 클러스터를 재구축하는 비주기적인 클러스터 재구축 방식을 사용한다. 본 논문에서는 클러스터를 주기적으로 재구축하지 않고 노드의 잔여 에너지 수준(level)을 여러 단계로 설정한 후 클러스터 헤드의 잔여 에너지 수준이 한 단계 낮아지면 클러스터를 재구축하는 방법을 제안한다. 또한 클러스터 헤드 선정 시 이웃 노드 수와 잔여 에너지 수준을 고려함으로써 클러스터 헤드의 분포를 균일하게 유지시켜 네트워크 수명을 연장시킨다. 본 제안 방식의 성능을 평가하기 위해서 Qualnet 기반의 시률레이션을 수행하였으며, ACAWT와 성능을 비교한 결과 제안 방식이 네트워크 수명 측면에서 우월함을 확인하였다.

키워드 : 무선 센서 네트워크, 클러스터링, 클러스터 헤드, 에너지 효율성

\section{1. 서 론}

대표적인 클러스터 기반의 무선 센서 네트워크 프로토콜 인 LEACH(Low-Energy Adaptive Clustering Hierarchy)

※ 이 논문은 2012년도 서울시립대학교 연구년교수 연구비에 의하여 연구 되었음.

† 비 회 원 : 텔러필드 연구원

† 종신회원 : 서울시립대학교 컴퓨터과학부 교수

논문접수:2013년 1월 22일

심사완료 : 2013년 3월 11일

* Corresponding Author:Sanghyun Ahn(ahn@uos.ac.kr)
프로토콜[4]에서는 주기적으로 클러스터 헤드들을 결정하며, 원하는 $\mathrm{CH}$ 의 비율 $P$ 에 대해서 모든 노드가 돌아가면서 $1 / p$ 라운드 내에 $\mathrm{CH}$ 가 될 수 있도록 함으로써 센서 노드들이 균일하게 에너지를 사용하게 한다. 그러나 확률적으로 $\mathrm{CH}$ 가 결정되기 때문에, $\mathrm{CH}$ 노드들이 균일하게 분포하지 못하고 한 곳에 몰리거나 전체 노드 수에 비해 너무 적을 수 있으 며, $\mathrm{CH}$ 노드에서 싱크까지 멀티홉(multi-hop)이 아닌 단일 홉(direct 또는 single hop)으로 전송하기 때문에 에너지 소 비도 비교적 큰 단점이 있다. 
ACAWT(Adaptive Clustering Algorithm via Waiting Timer)[5]는 LEACH 프로토콜과 달리 주기적으로 클러스터 를 재구축하지 않는다. 각 노드는 이웃 노드 수를 기반으로 대기(waiting) 타이머를 설정하고 이 타이머가 타임아웃 되 면 $\mathrm{CH}$ 노드가 되며, 따라서 $\mathrm{LEACH}$ 프로토콜에 비해 $\mathrm{CH}$ 들이 네트워크 전체에 균일하게 분포하게 된다. $\mathrm{CH}$ 노드의 잔여 에너지가 주어진 임계값보다 작아지면 이전에 $\mathrm{CH}$ 를 했던 노드들을 제외한 클러스터 멤버 노드들끼리 클러스터 를 재구축한다. 만약 클러스터 내 모든 노드들의 잔여 에너 지가 임계값보다 작아서 $\mathrm{CH}$ 노드가 될 수 있는 노드가 없 으면, 다시 대기 타이머를 설정한다. 그러나 $\mathrm{LEACH}$ 와 마찬 가지로 $\mathrm{CH}$ 에서 싱크까지 단일홉으로 전송하기 때문에 에너 지 소비가 비교적 큰 단점이 있다.

따라서 본 논문에서는 주기적으로 클러스터를 재구축하지 않고 필요할 때만 재구축하는 기법을 제안한다. $\mathrm{CH}$ 를 선택 하는 데 있어서 이웃 노드 수와 잔여 에너지 수준을 고려함 으로써 불필요한 클러스터 재구축을 방지하고 $\mathrm{CH}$ 노드의 분포를 균일하게 한다. 또한 잔여 에너지 수준을 여러 단계 로 설정함으로써 전반적인 노드 에너지 소비 패턴을 균등하 게 하고, $\mathrm{CH}$ 에서 싱크까지 멀티홉으로 전송하게 함으로써 에너지 효율성을 높이고 궁극적으로 네트워크 수명을 증가 시키는 기법을 제안한다

본 논문의 구성은 다음과 같다. 2장에서 제안하는 잔여 에너지 수준 기반의 동적 클러스터링 기법을 설명하고, 3장 에서 Qualnet[6] 기반의 시뮬레이션을 통해 ACAWT와 성 능을 비교 분석하고, 4장에서 결론을 맺는다.

\section{2. 잔여 에너지 수준 기반 동적 클러스터링}

본 논문에서는 잔여 에너지 수준을 여러 단계로 해서 클 러스터를 재구축하는 방법을 제안한다. $\mathrm{CH}$ 노드와 non-CH 노드 사이에서는 $P_{\text {low }}$ 로, $\mathrm{CH}$ 들 간에는 $P_{h i g h}$ 로 전송 파워를 다르게 한다. 또한 클러스터 내 통신은 경쟁(contention) 기 반의 $\mathrm{MAC}$ 프로토콜을 사용한다고 가정한다. 즉, TDMA 기 반의 $\mathrm{MAC}$ 프로토콜을 사용하는 방법들과 달리 $\mathrm{CH}$ 는 자신 의 클러스터에 속하는 노드들에 대해서 알지 못해도 되며, 따라서 클러스터 멤버 노드는 $\mathrm{CH}$ 에게 클러스터 조인(join) 메시지를 보내지 않아도 된다.

초기에, 모든 센서 노드들은 $\mathrm{CH}$ 를 결정하기 위하여 이웃 노드 개수와 자신의 잔여 에너지 수준을 바탕으로 다음과 같이 $\mathrm{CH}$ Notification $\operatorname{Timer}\left(T_{C H N}\right)$ 타이머를 설정한다.

$$
T_{\text {CHN }}=\frac{w_{e}}{w_{e} E+w_{n} N} \quad \text { (범위 } 0 \sim 1 \text { 초) }
$$

여기서 $N$ 은 이웃 노드 수, $E$ 는 잔여 에너지 수준 $(1,2,3$, $\cdots$, 숫자가 작을수록 잔여 에너지가 적음을 의미 $), w_{e}, w_{n}\left(w_{e}\right.$ $>w_{n}$, 정수)은 가중치이다. $w_{e}$ 와 $w_{n}$ 은 $T_{C H N}$ 값을 설정하
는 데 미치는 영향이 이웃 노드 개수는 거의 없는 반면, 잔 여 에너지 수준이 값에 영향을 더 주며, $w_{n}$ 값이 커질수록 $T_{C H N}$ 값을 설정하는 데 이웃 노드 개수의 영향이 커진다.

$T_{C H N}$ 이 타임아웃 되면, $P_{\text {low }}$ 로 Cluster Head Advertisement(CHA) 메시지를 1-홉 브로드캐스트하여 자 신이 $\mathrm{CH}$ 노드가 되겠다고 이웃 노드들에게 알린다. 이 $\mathrm{CHA}$ 메시지에는 자신의 $\mathrm{ID}$ 와 잔여 에너지 수준이 포함된 다. $T_{C H N}$ 이 타임아웃 전에 $\mathrm{CHA}$ 메시지를 받으면 $T_{C H N}$ 을 멈추고, $\mathrm{CH}$ 노드의 $\mathrm{ID}$ 와 잔여 에너지 수준을 $\mathrm{CH}$ 관리 테 이블에 저장한다. 여러 개의 $\mathrm{CHA}$ 메시지를 받으면 모두 저 장한다.

$\mathrm{CH}$ 의 잔여 에너지 수준이 한 단계 밑으로 낮아지면 Cluster Head Give-Up(CHG) 메시지를 $P_{\text {high }}$ 로 브로드캐스 트해서 더 이상 자신이 $\mathrm{CH}$ 가 아님을 주위의 non-CH 노드 들과 이웃 $\mathrm{CH}$ 들에게 알리고 클러스터 재구축을 시작한다. $\mathrm{CHG}$ 메시지를 받은 non- $\mathrm{CH}$ 노드들은 $\mathrm{CH}$ 관리 테이블에 서 $\mathrm{CHG}$ 메시지를 전송한 $\mathrm{CH}$ 노드를 삭제하고, $\mathrm{CH}$ 관리 테이블에 저장되어 있는 $\mathrm{CH}$ 노드가 없으면 $T_{C H N}$ 을 설정한 다. $\mathrm{CH}$ 관리 테이블에 1 개 이상의 $\mathrm{CH}$ 노드가 저장되어 있 으면, $T_{C H N}$ 을 설정하지 않는다. $\mathrm{CHG}$ 메시지를 보낸 노드도 주위에 non-CH 노드가 없거나 잔여 에너지 수준이 자신보 다 큰 non-CH 노드가 없을 수도 있기 때문에 $T_{C H N}$ 을 설정 한다. 이 후의 과정은 초기 클러스터를 구축하는 과정과 동 일하다.

Fig. 1은 초기 클러스터들(실선 원 및 이중 실선 원) 및 재구축된 클러스터(점선 원)를 보여준다. 처음에는 모든 노 드의 잔여 에너지가 동일하기 때문에 이웃 노드의 개수에 따라 $T_{C H N}$ 값이 달라진다. 3 번 노드의 이웃 노드 수가 4 로 가장 많기 때문에 $T_{C H N}$ 값이 가장 작으며, 따라서 3 번 노드 가 제일 먼저 $\mathrm{CHA}$ 메시지를 브로드캐스트하여 $\mathrm{CH}$ 가 된다. 이 $\mathrm{CHA}$ 메시지를 수신한 2번, 7 번, 8 번 노드는 $T_{C H N}$ 을 멈 추고 $\mathrm{CH}$ 노드가 되는 것을 포기한다. 다음으로 이웃 노드 수가 많은 6 번, 11 번 노드가 $\mathrm{CHA}$ 메시지를 브로드캐스트하 여 $\mathrm{CH}$ 가 되고, 그 다음 5 번, 14 번 노드가 $\mathrm{CH}$ 가 된다.

그 뒤, $\mathrm{CH}$ 노드였던 11번 노드(Fig. 1에서 해당 클러스터 는 이중 실선 원으로 표시되었음)가 잔여 에너지 수준이 한 단계 밑으로 내려가면서 $\mathrm{CHG}$ 메시지를 브로드캐스트해서 이웃 노드인 7 번, 12 번, 15 번 노드에게 자신이 더 이상 $\mathrm{CH}$ 노드가 아님을 알린다. 7 번, 15 번 노드는 자기 이웃에 각각 $\mathrm{CH}$ 노드인 3 번, 14 번 노드가 존재하기 때문에 $T_{C H N}$ 을 설정 하지 않고, 이웃에 $\mathrm{CH}$ 노드가 없는 12 번 노드와 $\mathrm{CH}$ 노드였 던 11 번 노드만 $T_{C H N}$ 을 설정한다. 그러면 $T_{C H N}$ 이 더 작은 12 번 노드가 새롭게 $\mathrm{CH}$ 가 된다.

$\mathrm{CH}$ 는 싱크로 데이터를 보내기 전에 싱크로의 경로를 설 정한다. 경로를 설정하기 위해 모든 $\mathrm{CH}$ 는 자신이 $\mathrm{CH}$ 가 된 후, $\mathrm{CH}$ 가 모두 선정되기를 기다리기 위해 $T_{C H N, M}\left(T_{C H N}\right.$ 의 최대값) $-T_{C H N}$ 초 후에 $P_{h i g h}$ 로 RREQ(Route Request) 메 시지를 1-홉 브로드캐스트한다. 싱크가 근처 $\mathrm{CH}$ 로부터 처 음 RREQ 메시지를 수신하면, $P_{h i g h}$ 로 $\mathrm{RREP}$ (Route Reply) 메시지를 브로드캐스트한다. 이 RREP 메시지를 수신한 $\mathrm{CH}$ 


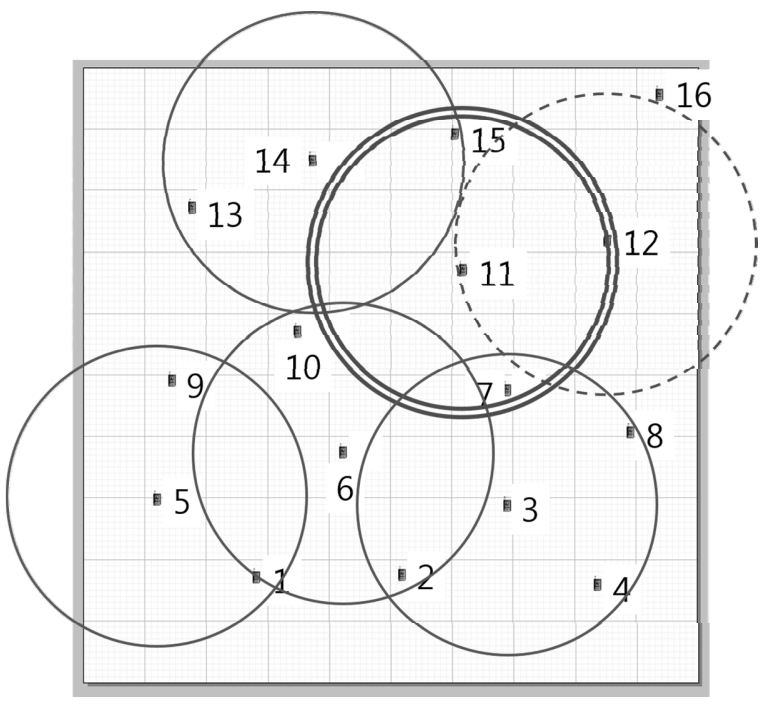

Fig. 1. Initial clusters (solid line circle, double solid link circle) and a reconstructed cluster (dotted line circle) (where node 16 is the sink)

들은 싱크로의 경로를 설정하고, 다시 $\mathrm{RREP}$ 메시지를 $P_{h i g h}$ 로 이웃 $\mathrm{CH}$ 들에게 브로드캐스트한다. Fig. 2는 $\mathrm{CH}$ 들이 $\mathrm{RREQ}$ 메시지를 전송하고 RREP 메시지를 받아서 싱크(16 번 노드)로의 경로를 설정한 것을 보여준다. 5 번 $\mathrm{CH}$ 는 데이 터를 6 번 $\mathrm{CH}$ 에게 전송하고, 6 번 $\mathrm{CH}$ 는 다시 11 번 $\mathrm{CH}$ 에게, 11 번 $\mathrm{CH}$ 는 싱크에게 전송하게 된다.

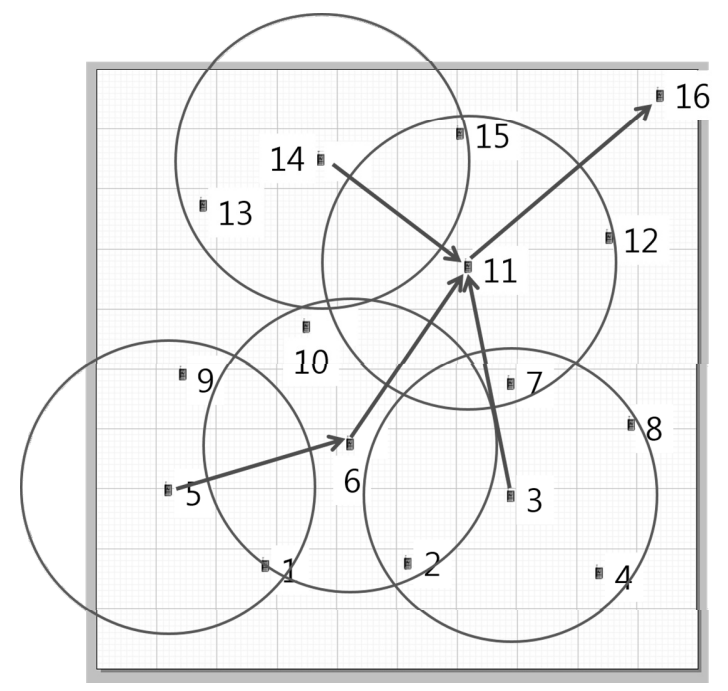

Fig. 2. Routes from $\mathrm{CHs}$ to the sink

\section{3. 성능 분석}

제안 방식과 ACAWT의 성능 비교를 위해 Qualnet 시뮬 레이터[6]를 이용해서 시뮬레이션을 수행했으며, 노드의 배 터리 모델은 Linear 모델, 최대 배터리 용량은 10mA.h, 에 너지 모델은 Generic 모델을 사용했다. MAC 프로토콜로는 $\mathrm{IEEE} \mathrm{802.11을} \mathrm{사용했으며,} w_{e}, w_{n}$ 은 각각 10 과 1 로 설정했

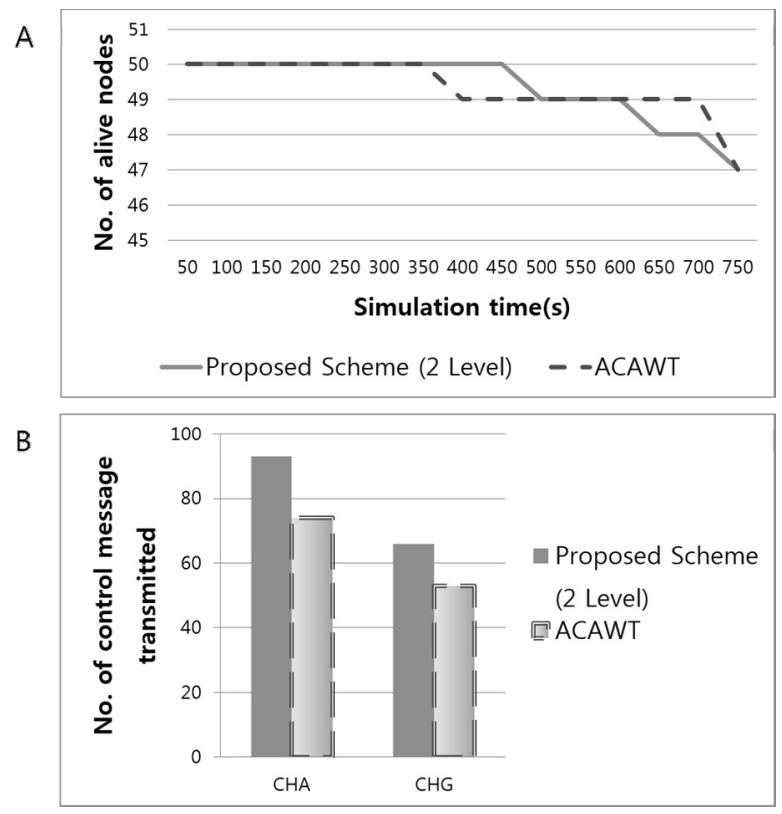

Fig. 3. Performance comparison of the proposed mechanism with 2 energy levels and ACAWT: A, the network lifetime in terms of the number of alive nodes; $\mathrm{B}$, the number of $\mathrm{CHA}$ and $\mathrm{CHG}$ messages

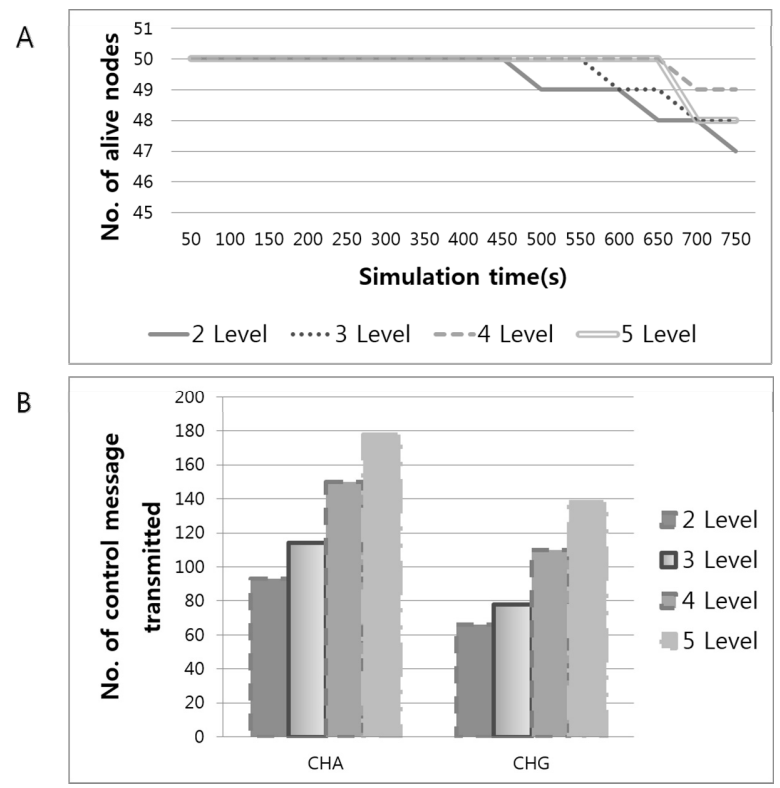

Fig. 4. Performance of the proposed mechanism: $A$, the network lifetime in terms of the number of alive nodes; B, the number of $\mathrm{CHA}$ and $\mathrm{CHG}$ messages

고, $\mathrm{ACAWT}$ 의 경우 $\mathrm{CH}$ 와 싱크 간에 멀티홉으로 통신하게 구현했다. 네트워크 토폴로지로는 $2000 \mathrm{~m}$ x $2000 \mathrm{~m}$ 영역에 50 개의 센서 노드를 랜덤하게 배치하고 1 개의 싱크를 우측 상단에 배치했다.

Fig. 3은 제안 기법의 잔여 에너지 수준을 2 개로 했을 때 와 ACAWT를 시률레이션 시간에 따른 생존 노드 수와 클러 스터 (재)구축에 따른 제어 메시지 측면에서 비교한 것으로, 
제안 기법이 제어 메시지를 더 많이 전송하지만 네트워크 수 명 측면에서 ACAWT보다 성능이 우수함을 알 수 있다.

Fig. 4는 제안 기법의 잔여 에너지 수준을 2개, 3개, 4개, 5 개로 했을 때의 시뮬레이션 결과이다. 잔여 에너지 수준이 많아질수록 $\mathrm{CHA}, \mathrm{CHG}$ 메시지를 더 많이 전송하며, 잔여 에너지 수준이 4개, 5개일 때 네트워크 수명이 가장 좋다. 650 초 이후에는 잔여 에너지 수준이 4개일 때가 가장 좋은 결과를 보였다.

\section{4. 결 론}

무선 센서 네트워크의 대표적인 클러스터링 방식인 $\mathrm{LEACH}$ 의 경우 주기적으로 클러스터를 재구축하기 때문에 에너지를 불필요하게 소비하고, $\mathrm{CH}$ 를 확률적으로 선택하기 때문에 $\mathrm{CH}$ 들이 균일하게 분포하지 못하게 되는 문제가 있 다. ACAWT는 클러스터 재구축을 주기적으로 하지 않고 잔여 에너지 수준(임계치)을 이용해서 필요시 클러스터를 재구축하는 방법을 사용한다. 그러나 단일 임계치를 사용하 기 때문에 노드 에너지를 효율적으로 균등하게 사용하지 못 하는 단점이 있다. 따라서 본 논문에서는 다수의 잔여 에너 지 수준을 사용하는 방법을 제안했으며, 시뮬레이션을 통해 제안 방식이 ACAWT에 비해 노드 에너지 소비를 보다 균 등하게 하고 결과적으로 네트워크 수명을 증가시킴을 입증 했다.

\section{참 고 문 헌}

[1] K. Subbu and X. Li, "SFRP: A selective flooding-based routing protocol for clustered wireless sensor networks," Radio and Wireless Symposium (RWS), 2010.

[2] C.-C. Kao, J. Wu, and S.-C. Chen, "Energy Efficient Clustering Communication Protocol for Wireless Sensor Network," Advanced Communication Technology (ICACT), 2010.
[3] A. K. Tripathy and S. Chinara, "Comparison of Residual Energy-Based Clustering Algorithms for Wireless Sensor Network," ISRN Sensor Networks, 2012.

[4] W. Heinzelman, A. Chandrakasan, and H.Balakrishnan, "Energy-Efficient Communication Protocol for Wireless Microsensor Networks," Proceedings of the 33rd Hawaii International Conference on System Sciences, 2000.

[5] C.-Y. Wen and W. A. Sethares, "Adaptive Decentralized Re-Clustering for Wireless Sensor Networks," 2006 IEEE International Conference on System, Man, and Cybernetics, 2006.

[6] http://www.scalable-networks.com/content/products/qualnet.

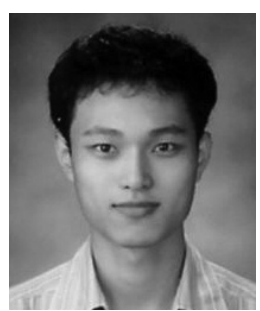

김 환

e-mail :gwanunjang@naver.com

2010년 충남대학교 전자전파정보통신전공 (학사)

2013년 서울시립대학교 컴퓨터통계학과 (석사)

2013년 현 재 텔러필드 연구원 관심분야: Wireless Sensor Network, MANET

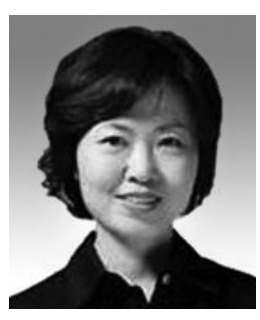

안 상 현

e-mail:ahn@uos.ac.kr 1986년 서울대학교 컴퓨터공학과(학사) 1988년 서울대학교 컴퓨터공학과(석사) 19933년 미네소타대학교 컴퓨터과학과 (박사)

1988년 1989년 (주)데이콤 연구원

1994년 1998년 세종대학교 컴퓨터학과 교수 1998년 현 재 서울시립대학교 컴퓨터과학부 교수

관심분야: Wireless Sensor Network, MANET, VANET, 인터넷, 라우팅 프로토콜, 유무선통신망 